\title{
PENGARUH TEKNIK BUDIDAYA KUBIS TERHADAP DIVERSITAS ARTHROPODA DAN INTENSITAS SERANGAN Plutella xylostella L. (LEPIDOPTERA: PLUTELLIDAE)
}

Oleh:

\section{SYARIEF *)}

\section{ABSTRAK}

Penelitian ini dilaksanakan di desa Balung Lor, kecamatan Balung, kabupaten Jember, selama tiga bulan dimulai September sampai dengan Nopember 2013, bertujuan untuk mengetahui pengaruh teknik budidaya kubis terhadap diversitas arthropoda dan intensitas serangan $P$. xylostella L. Indeks keanekaragaman arthropoda dianalisis menggunakan indeks keanekaragaman Shanon-Wiener $\left(\mathrm{H}^{\prime}\right)$, indeks domonansi Simpson (D) dan indeks kemerataan jenis (E). Untuk membedakan intensitas serangan P. xylostella $\mathrm{L}$. menggunakan uji $\mathrm{T}$ pada taraf $5 \%$. Kesimpulan penelitian ini sebagai berikut: diversitas arthropoda pada agroekosistem kubis yang dibudidayakan secara organik maupun konvensional menunjukkan jumlah kelas, ordo, famili dan spesies yang sama yaitu dua kelas, tujuh ordo, empat belas famili dan enam belas spesies. Status dalam jaring makanan meliputi hama terdiri atas sembilan spesies yaitu Oxya chinensis (Orthoptera: Acrididae), P. xylostella L. (Lepidoptera: Plutellidae), Agrotis ipsilon Hufnage (Lepidoptera: Noctuidae), Crocidolomia pavonana Zell. (Lepidoptera: Pyralidae), Myzus persicae Sulz. (Homoptera: Aphididae), Spodoptera litura F.( Lepidoptera: Noctuidae), Chrysodeixis chalcites Esp. (Lepidoptera: Noctuidae), Gryllus assimilis (Orthoptera: Gryllidae) dan Phyllotretta cruciferae (Coleoptera: Chrysomilidae). Lima spesies predator meliputi: Leptogaster sp (Diptera: Asilidae), Oxyopes javanus (Araneae: Oxyopidae), Lycosa sp. (Araneae: Lycosidae), Mantis religeosa (Araneae: Mantidae) dan Solenopsis geminata F. (Hymenoptera: Formicidae), satu parasitoid Diadegma semiclausum Hellen. (Hymenoptera: Ichneumonidae) dan satu detrivora Musca domestica (Diptera: Muscidae). Jumlah individu hama, predator, parasitoid maupun detrivora pada agroekosistem kubis yang dibudidayakan secara organik menunjukkan lebih besar dibanding konvensional. Indeks diversitas arthropoda pada teknik budidaya organik lebih tinggi dibanding konvensional. Intensitas serangan $P$. xylostella $\mathrm{F}$. pada teknik budidaya organik dibanding konvensional menunjukkan berbeda tidak nyata.

Kata Kunci: teknik budidaya kubis, diversitas arthropoda, intensitas serangan P. xylostella $\mathrm{L}$. 
M. Syarief, Pengaruh Teknik Budidaya Kubis Terhadap Diversitas Arthropoda Dan Intensitas Serangan Plutella xylostella L. (Lepidoptera : Plutellidae)

\section{PENDAHULUAN}

Hama ulat daun kubis $P$. xylostella L. (Lepidoptera: Plutellidae) merupakan salah-satu jenis hama utama di pertanaman kubis. Intensitas serangan berat dapat menyebabkan tanaman kubis tidak membentuk krop dan gagal panen. Kehilangan hasil dapat mencapai 100 persen (Sudarwohadi, 1975 dalam Setiawati, 2000). Penggunaan insektisida sintetis secara terus menerus dapat menimbulkan resistensi terhadap $P$. xylostella $\mathrm{L}$. dan membahayakan parasitoid D. semiclausum (Sastrosiswojo dkk., 1989). Musnahnya musuh alami ini dapat mengganggu stabilitas diversitas arthropoda.

Diversitas arthropoda dalam agroekosistem kubis sangat penting manfaatnya. Berdasarkan komposisi spesies artropoda dalam agroekosistem kubis diharapkan dapat diperoleh rekomendasi pengendalian hama yang optimal. Jasa-jasa ekologis yang diemban oleh diversitas arthropoda, diantaranya jasa pengendali hayati (predator, parasitoid, detrivora) untuk mengendalikan hama, sangatlah penting bagi pertanian berkelanjutan. Dengan adanya kemajuan pertanian modern, prinsip ekologi tersebut telah diabaikan secara berkesinambungan, akibatnya agroekosistem menjadi tidak stabil. Perusakan tersebut menimbulkan munculnya hama secara berulang dalam sistem pertanian (Emden and Dabrowski, 1997).

Mekanisme-mekanisme alami seperti predatisme, parasitisme, patogenisitas, persaingan intraspesies dan interspesies, suksesi, produktivitas, stabilitas dan keanekaragaman hayati dapat dimanfaatkan untuk mencapai pertanian berkelanjutan. Konsekuensi dari pengurangan keanekaragaman hayati akan lebih jelas terlihat pada pengelolaan hama pertanian (Swift et. al., 1996).

Penelitian bertujuan untuk mengetahui pengaruh pengaruh teknik budidaya kubis terhadap diversitas arthropoda dan intensitas serangan $P$. xylostella $\mathrm{L}$.

\section{METODE PENELITIAN}

Penelitian dilaksanakan di Desa Balung Lor, Kecamatan Balung, Kabupaten Jember.Waktu penelitian September sampai dengan Nopember
2013. Penelitian terdiri atas dua perlakuan yang memiliki teknik budidaya yang berbeda. Perlakuan pertama adalah budidaya kubis secara organik, yaitu menggunakan input produksi pupuk organik (campuran pupuk kandang kotoran sapi dan kompos jerami bekas budidaya jamur merang dengan perbandingan 1:1 dengan dosis 30 ton/ha. Pestisida organik menggunakan insektisida nabati berbahan aktif azadirachtin, Nematoda Entomopatogen, NEP Steinernema spp.dengan interval satu minggu. Perlakuan kedua adalah budidaya kubis secara konvensional yaitu menggunakan input produksi pupuk anorganik (pupuk majemuk NPK (15:15:15) dengan dosis satu ton/ha diberikan waktu tanam, pupuk urea $200 \mathrm{~kg} / \mathrm{ha}$ pada waktu tanam dan 200 $\mathrm{kg} / \mathrm{ha}$ pada 4 MST. Pengendalian hama menggunakan insektisida berbahan aktif permetrin dengan interval satu minggu, konsentrasi $2 \mathrm{ml} /$ liter, volume semprot 500 liter/ha. Tanaman kubis yang digunakan ialah varietas Green coronet dengan jarak tanam $40 \mathrm{~cm}$ x $60 \mathrm{~cm}$.

Alat yang dipakai dalam penelitian ini meliputi : pan trap, sweep net, knapsack sprayer, botol, gunting, mikroskop binokuler, mistar, kamera digital, buku The Pest of Crops in Indonesia (Kalshoven, 1981). Bahan yang digunakan dalam penelitian ini meliputi : tanaman kubis varietas Green coronet, alkohol $70 \%$, pupuk organik (campuran pupuk kandang kotoran sapi dan kompos jerami bekas budidaya jamur merang dengan perbandingan 1:1, pupuk majemuk NPK (15-15-15), insektiisda berbahan aktiv azadirachtin, NEP Steinernema sp., insektisida berbahan aktif permetrin.

Keanekaragaman arthropoda dianalisis menggunakan indeks keanekaragaman ShanonWiener (H') (1984) dalam Soegianto dan Agoes (1994) dengan persamaan berikut.

$$
\mathbf{H}^{\prime}=-\Sigma \text { pi In pi }
$$

H' adalah indeks keanekaragaman jenis, $\mathrm{Pi}$ adalah kelimpahan relatif spesies $\mathrm{ke}-\mathrm{I}(\mathrm{Ni} / \mathrm{Nt}), \mathrm{Ni}$ adalah Jumlah individu spesies ke-i, Nt adalah jumlah total untuk semua individu dan Ln adalah logaritma natural. Selanjutnya nilai indeks tersebut dibandingkan untuk tiap lokasi pengamatan. Nilai indeks keanekaragaman jenis umumnya berkisar 0-7 dan memiliki beberapa kriteria yaitu rendah untuk 
M. Syarief, Pengaruh Teknik Budidaya Kubis Terhadap Diversitas Arthropoda Dan Intensitas Serangan Plutella xylostella L. (Lepidoptera : Plutellidae)

$\mathrm{H}^{\prime}=0$ - 2; sedang jika H'> 2 - 3; dan tinggi jika H' $>3$ (Barbour et al., 1987 dalam Ningsih, 2008).

Status kondisi komunitas ditentukan dengan menggunakan indeks dominansi Simpson dan indeks kemerataan jenis (Odum, 1997 dalam Fachrul,
2007). Indeks dominansi Simpson menggunakan rumus berikut.

$$
\mathrm{D}=\sum_{\mathrm{i}=1}^{\mathrm{s}}\left[\frac{\mathrm{Ni}}{\mathrm{N}}\right]^{2}
$$

$\mathrm{D}=$ Indeks dominansi - Simpson, $\mathrm{Ni}=$ Jumlah individu jenis $\mathrm{ke}-\mathrm{i}, \mathrm{N}=$ Jumlah total individu, $\mathrm{S}=$ Jumlah jenis. Indeks dominansi -Simpson bernilai antara $0-1$ dengan deskripsi sebagai berikut : $\mathrm{D}=0$ berarti tidak terdapat jenis yang mendominasi jenis lainya atau komunitas berada dalam kondisi Stabil. D
$=1$, berarti terdapat jenis yang mendominasi jenis lainya atau komunitas berada dalam kondisi labil karena terjadi tekanan ekologis.

Indeks kemerataan jenis menunjukkan penyebaran individu spesies dalam suatu komunitas, dihitung menggunakan rumus berikut.

\section{$E=H^{\prime} / \operatorname{Ln} S$.}

E adalah indeks kemerataan jenis; H' adalah indeks keanekaragaman jenis dan $\mathrm{S}$ adalah jumlah spesies. Nilai indeks kemerataan jenis ini berkisar antara $0-1$ dengan deskripsi sebagai berikut : $\mathrm{E}=0$, kemerataan antara spesies rendah, artinya kekayaan individu yang dimiliki masing-masing spesies sangat jauh berbeda $\mathrm{E}$

$$
\mathrm{I}=\frac{\sum\left(\mathrm{n}_{\mathrm{i}} \mathrm{v}_{\mathrm{i}}\right)}{\mathrm{NZ}} \times 100 \%,
$$

kerusakan $>50 \%$, berat, kerusakan $>30 \%-50 \%$, cukup berat, kerusakan $>15 \%-30 \%$, ringan, kerusakan $>0 \%$ $15 \%$ dan tidak ada serangan, kerusakan $0 \%$. Untuk membedakan intensitas serangan $P$. xylostella $\mathrm{L}$. antar perlakuan menggunakan uji T pada taraf $5 \%$.
$=1$, kemerataan antar spesies relatif merata atau jumlah individu masing-masing spesies relatif sama.

Intensitas serangan $P$. xylostella $\mathrm{L}$. dihitung menggunakan persamaan menurut Departemen Pertanian (2000) dalam Djafaruddin (2000) berikut.

\section{HASIL DAN PEMBAHASAN}

Arthropoda yang didapat pada kebun kubis yang dibudidayakan secara organik dan secara konvensional di identifikasi lalu dikelompokkan berdasarkan taksonomi, yaitu kelompok kelas, ordo,

\begin{tabular}{|l|l|l|l|l|l|}
\hline No & \multicolumn{1}{|c|}{ Kelas } & \multicolumn{1}{|c|}{ Ordo } & \multicolumn{1}{c|}{ Famili } & \multicolumn{1}{c|}{ Spesies } & Status \\
\hline 1 & insekta & Orthoptera & Acrididae & O. chinensis (belalang hijau) & Hama \\
\hline 2 & Insekta & Lepidoptera & Plutellidae & P. xylostella L.(ulat tritip) & Hama \\
\hline 3 & Insekta & Lepidoptera & Noctuidae & A.ipsilon Hufnage (ulat tanah) & Hama \\
\hline 4 & Insekta & Lepidoptera & Pyralidae & C. pavonana F.(ulat crocci) & hama \\
\hline 5 & Insekta & Diptera & Asilidae & Leptogaster s (capung) & Predator \\
\hline 6 & Insekta & Homoptera & Aphididae & M. persicae Sulz. (kutu daun) & Hama \\
\hline 7 & Arachnida & Araneae & Oxyopidae & O. javanus (laba-laba) & Predator \\
\hline 8 & Insekta & Lepidoptera & Noctuidae & S. litura F.(ulat grayak) & Hama \\
\hline 9 & Insekta & Lepidoptera & Noctuidae & C. chalcites Esp. (ulat jengkal) & Hama \\
\hline 10 & Arachnida & Araneae & Lycosidae & Lycosa sp. (laba-laba) & Predator \\
\hline 11 & Insekta & Orthoptera & Mantidae & M. religeosa (belalang sembah) & Predator \\
\hline
\end{tabular}


M. Syarief, Pengaruh Teknik Budidaya Kubis Terhadap Diversitas Arthropoda Dan Intensitas Serangan Plutella xylostella L. (Lepidoptera : Plutellidae)

\begin{tabular}{|l|l|l|l|l|l|}
\hline 12 & Insekta & Orthoptera & Gryllidae & G. assimilis (jangkrik) & Hama \\
\hline 13 & Insekta & Coleoptera & Chrysomilidae & P. cruciferae (kutu kumbang) & Hama \\
\hline 14 & Insekta & Hymenoptera & Ichneumonidae & D. semiclausum Hellen. & Parasitoid \\
\hline 15 & Insekta & Diptera & Muscidae & M. domestica (Lalat rumah) & detrifora \\
\hline 16 & Insekta & Hymenoptera & Formicidae & S. geminata F. (semut api) & predator \\
\hline
\end{tabular}

Berdasarkan Tabel 1 dapat diketahui bahwa komposisi arthropoda menurut taksonomi dan status dalam agroekosistem pada lahan kubis yang dibudidayakan secara organik maupun konvensional menunjukkan jumlah kelas, ordo, famili dan spesies yang sama.
Pengelompokan arthropoda berdasarkan fungsi jaring makanan dalam agroekosistem tanaman kubis disajikan dalam Gambar 1.berikut.

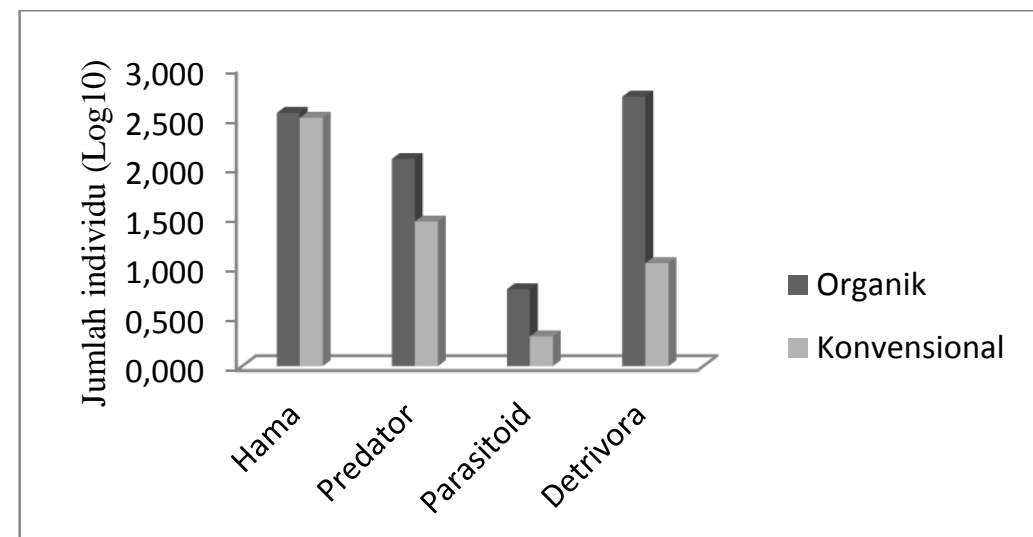

Fungsi jaring makanan

Gambar 1. Hubungan fungsi jaring makanan dengan jumlah individu

Berdasarkan Gambar 1., menunjukkan bahwa jumlah individu hama, predator, parasitoid maupun detrivora antara teknik budidaya organik dan konvensioanal adalah tidak sama . Teknik budidaya organik menunjukkan jumlah invidu lebih banyak dibanding teknik budidaya konvensional, hal ini dapat disebabkan oleh perlakuan dengan insektisida sintetik pada teknik budidaya konvensional lebih efektif dan tidak selektif dalam membunuh arthropod yang ada dibanding dengan insektisida organik.

Kurva kelimpahan spesies disajikan dalam Gambar 2 berikut.

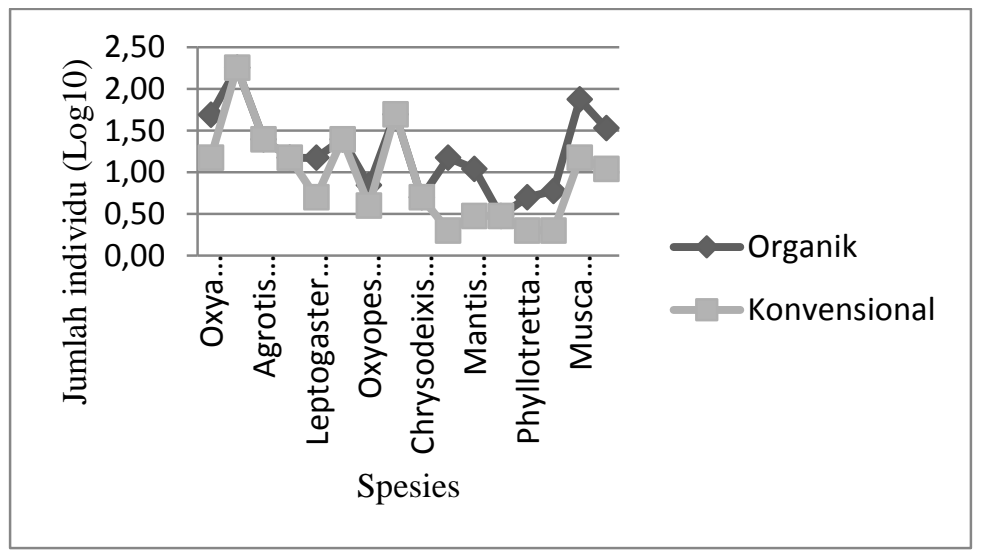


M. Syarief, Pengaruh Teknik Budidaya Kubis Terhadap Diversitas Arthropoda Dan Intensitas Serangan Plutella xylostella L. (Lepidoptera : Plutellidae)

Berdasarkan Gambar 2., jumlah individu masing-masing spesies pada teknik budidaya organik dan konvensioanal tidak sama. Teknik budidaya organik menunjukkan jumlah invidu masing-masing spesies lebih banyak dibanding teknik budidaya konvensional, hal ini dapat disebabkan perlakuan dengan insektisida sintetik lebih efektif dan tidak selektif dalam membunuh arthropod yang ada dibanding dengan insektisida organik.

Indeks keanekaragaman Shanon-Wiener $\left(\mathrm{H}^{\prime}\right)$, indeks domonansi Simpson (D) dan indeks kemerataan jenis (E) pada lahan yang menggunakan teknik budidaya organik dan konvensional disajikan dalam Tabel 2 berikut.

Tabel 2. Indeks keanekaragaman Shanon-Wiener (H'), indeks domonansi Simpson (D) dan indeks kemerataanjenis (E)

\begin{tabular}{|l|c|c|}
\hline \multicolumn{1}{|c|}{ Peubah } & Budidaya organik & Budidaya konvensional \\
\hline indeks keanekaragaman Shanon-Wiener $\left(\mathrm{H}^{\prime}\right)$ & 1.043 & 1.051 \\
\hline indeks domonansi Simpson (D) & 0.551 & 0.636 \\
\hline indeks kemerataan jenis (E) & 0.420 & 0.379 \\
\hline
\end{tabular}

Berdasarkan kriteria dalam Barbour et al., 1987, kisaran indeks keanekaragaman Shanon-Wiener (H') tergolong rendah. Indeks domonansi Simpson (D) tidak ada dominansi dan komunitas mengalami tekanan ekologis. Indeks kemerataan jenis (E) pengelolaan hama secara organik lebih merata dan berada dalam keadaan lebih stabil dibanding konvensional.

Intensitas serangan $P$. xylostella $\mathrm{F}$. pada 5 MST disajikan dalam Tabel 3 berikut.

Tabel 3. Intensitas serangan P. xylostella F. pada 5 MST (data ditransfer ke Arc Sin\%)

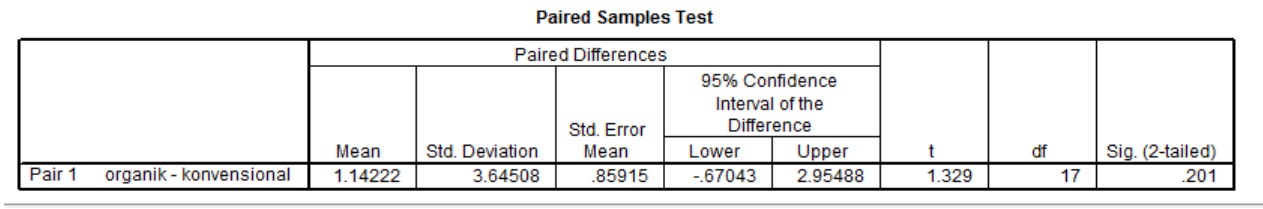

Berdasarkan uji t pada taraf 5\%, Intensitas serangan $P$. xylostella F. pada 5 MST. $\quad \mathrm{t}$ hitung $<\mathrm{t}$ Tabel, $(1.329)<\mathrm{t}$ tabel $(2.11)$, ini menunjukkan perlakuan organik berbeda tidak nyata terhadap konvensional

\section{KESIMPULAN}

Penelitian berjudul "Pengaruh teknik budidaya kubis terhadap diversitas arthropoda dan intensitas serangan Plutella xylostella L. (Lepidoptera: Plutellidae)" dapat disimpulkan sebagai berikut:

1. Diversitas arthropoda pada agroekosistem kubis yang dibudidayakan secara organik maupun konvensional menunjukkan jumlah kelas, ordo, famili dan spesies yang sama yaitu dua kelas, tujuh ordo, empat belas famili dan enam belas spesies. Status dalam jaring makanan meliputi hama terdiri atas sembilan spesies yaitu $O$. chinensis (Orthoptera: Acrididae), P. xylostella L. sehingga teknik budidaya secara organik dapat direkomendasikan dengan kondisi yang relatif sama dengan agroekosistem penelitian.

(Lepidoptera: Plutellidae), A. ipsilon Hufnage (Lepidoptera: Noctuidae), $C$. pavonana Zell. (Lepidoptera: Pyralidae), $M$. persicae Sulz. (Homoptera: Aphididae), $S$. litura F.( Lepidoptera: Noctuidae), $C$. chalcites Esp. (Lepidoptera: Noctuidae), $G$. assimilis (Orthoptera: Gryllidae) dan $P$. cruciferae (Coleoptera: Chrysomilidae). Lima spesies predator meliputi: L. (Diptera: Asilidae),O. javanus (Araneae: Oxyopidae), Lycosa sp. (Araneae: Lycosidae), $M$. religeosa (Araneae: Mantidae) dan $S$. geminata F. (Hymenoptera: Formicidae), satu parasitoid D. semiclausum Hellen. (Hymenoptera: Ichneumonidae) dan satu detrivora M. domestica (Diptera: Muscidae). 
M. Syarief, Pengaruh Teknik Budidaya Kubis Terhadap Diversitas Arthropoda Dan Intensitas Serangan Plutella xylostella L. (Lepidoptera : Plutellidae)

2. Jumlah individu hama, predator, parasitoid maupun detrivora pada agroekosistem kubis yang dibudidayakan secara organik menunjukkan lebih besar dibanding konvensional.

\section{DAFTAR PUSTAKA}

Djafaruddin. 2000. Dasar-Dasar Pengendalian Penyakit Tanaman. Jakarta: Bumi Aksara.

Emden, H.F \& Z.T. Dabrowski. 1997. Issues of biodiversity in pest management. Insect Science and Applications 15:605-620.

Fachrul, M. F. 2007. Metode Sampling Bioekologi. Jakarta: PT Bumi Aksara.

Kalshoven, L.G.E. (1981). Pests of Crops in Indonesia. Revised and translated by P.A. van der Laan and G.H.L. Rothschild. Jakarta: P.T. Ichtiar Baru - Van Hoeve,

Soegianto dan Agoes. 1994. Ekologi Kuantitatif. Surabaya: Usaha Nasional.

Sastrosiswojo, S., T. Koestoni dan A. Sukwida. 1989. Status Resistensi Plutella xylostella L. Strain Lembang terhadap Beberapa Jenis Insektisida Golongan Organo Fosfat, Piretroid Sintetik dan enzoil Urea. Bul. Penel. Hort. 18(1):8593.

Setiawati, W. 2000. Pengendalian hama kubis Plutella xylostella L. dan Crocidolomia binotalis Zell. Dengan Spinosad 25 SC serta pengaruhnya terhadap Parasitoid Diadegma semiclausum Hellen. J. Hort. 10(1): $30-39$.

Swift, M.S., J. Vandermer, P.S. Ramakrishnan, J.M. Anderson, C.K. Ong \& B.A. Hawkins. 1996. Biodiversity and agroecosystem function, dalam Functional Roles of Biodiversity: A Global Perspective. Ed. H.A. Mooney. John Wiley \& Sons, New York. pp.261-298.
3. Indeks diversitas arthropoda pada teknik budidaya organik lebih tinggi dibanding konvensional.

4. Intensitas serangan $P$. xylostella $\mathrm{F}$. pada teknik budidaya organik dibanding konvensional menunjukkan berbeda tidak nyata. 